\title{
Usage of herbal medicine and over the counter medications among diabetic patients visiting a primary care clinic- do we need public awareness?
}

\author{
Yousef Abdullah Al Turki \\ Received: 8 April 2013 / Accepted: 16 November 2013 /Published online: 3 December 2013 \\ (C) Research Society for Study of Diabetes in India 2013
}

Diabetic patients are more likely to use herbal medicine and over the counter medications because of the chronic course of the disease [1]. The use of herbal product has risen, whereas discussion of such use with medical professionals remains suboptimal [2]. As herbal medicines are used by increasing numbers of people, family physicians and pharmacists must be knowledgeable about their safety. This requires appreciation of the magnitude of use, as well as regulations under which the products are marketed that may affect their safety [3]. Diabetic patients spent almost as much money on overthe-counter supplements and alternative medications together as they did on their diabetic medications. One-third of diabetic patients are taking alternative medications that they consider efficacious [4]. The aim of this study was to highlight the usage of herbal medicine and over the counter medications among diabetic patients.

Cross sectional study carried out at outpatient primary care clinic, in a tertiary teaching hospital, Riyadh, Saudi Arabia during 2012. The Research has been approved from institutional review board ethical committee, King Khalid University hospital, college of Medicine, king Saud University, project number E-12-821. All diabetic patients visiting a primary care clinic was seen by a consultant family medicine and interviewed about their usage of herbal medicine and over the counter medications without con-

Table 1 Usage of herbal medicine among diabetic patients

\begin{tabular}{lll}
\hline Usage of herbal medicine & Frequency & Percentage \\
\hline Used herbal medicine & 17 & 17 \\
Not used herbal medicine & 83 & 83 \\
Total & 100 & 100 \\
\hline
\end{tabular}

\section{Y. A. Al Turki $(\bowtie)$}

Department of Family and Community Medicine,

College of Medicine, King Saud University, P.O Box 28054,

Riyadh 11437, Saudi Arabia

e-mail: yalturki@ksu.edu.sa
Table 2 Usage of over the counter medications among diabetic patients

\begin{tabular}{lll}
\hline Usage of over the counter medications & Frequency & Percentage \\
\hline Used over the counter medications & 12 & 12 \\
Not used over the counter medications & 88 & 88 \\
Total & 100 & 100 \\
\hline
\end{tabular}

sulting their treating physician. Data was entered using Statistical package of social science version 17.

The present study showed that the number of diabetic patients who used herbal medicine without consulting their treating physicians was $17 \%$ Table 1 (17 patients out of 100) and the number of diabetic patients who used over the counter medications without consulting their treating physicians was $12 \%$ Table 2 (12 patients out of 100). Over the counter medications means any medications used without prescription from physician. In Conclusion: Diabetic patients need to be council, educate and convince about avoiding using over the counter medications and herbal medicine without consulting their treating physicians. Further community base study is recommended to study in depth why diabetic patients used herbal medicine and over the counter medications?

Conflicts of interest None.

\section{References}

1. Huri HZ, Poh Lian G, Hussain S, Pendek R, Widodo R. A survey amongst complementary alternative medicine (CAM) users with type 2 diabetes. Int J Diabetes Metab. 2009;17:9-15.

2. Bruno J, Ellis J. Herbal use among US elderly: 2002 national health interview survey. Ann Pharmacother. 2005;39:643-8.

3. Boullata J, Nace A. Safety issues with herbal medicine. Pharmacotherapy. 2000;20:257-69.

4. Ryan E, Pick M, Marceau C. Use of alternative medicines in diabetes mellitus. Diabet Med. 2001;18:242-5. 